\title{
Engaging Graduate Students with an Images of Research Competition
}

\section{Ms. Alison Henry, University of Alberta}

Alison Henry is the Engineering Librarian at the University of Alberta. She earned a Bachelor's degree in Chemical Engineering from Queen's University and spent several years working in Environmental Health and Safety in the Chemical Industry before obtaining her MLIS. Her research interests focus on research impact analysis and information literacy in engineering education.

\section{Lucinda Johnston, University of Alberta}

Lucinda is a Public Services Librarian specializing in Music and Drama, who values non-traditional, creative, arts-based research activities and communications. She currently serves on the University of Alberta Libraries' Images of Research committee. 


\title{
Engaging Graduate Students With an Images of Research Competition
}

\begin{abstract}
Once a year, graduate students are invited to showcase their research by submitting a high-resolution image, accompanied by a title and short, plain-language description explaining how the image represents their research, to the University of Alberta (UAlberta) Libraries' Images of Research competition. This competition provides graduate students the opportunity to tell the story of their research to the broader campus community, encourages them to develop professional communication skills, and fosters community, while leveraging library expertise and spaces to promote the research occurring on campus. Submissions that meet eligibility requirements are judged on their originality, aesthetic appeal, relationship between the image and the student's research, and clarity of the accompanying title and description by a panel consisting of faculty, graduate students, and design or communications professionals. Twenty-four images are selected as semi-finalists, with six prize winners, including a People's Choice award, chosen from this group. Prize winners are announced at a catered reception in the library, where an exhibition of winning and semi-finalist entries remains on display for approximately one month. Winner and semi-finalist images are deposited in ERA [1], UAlberta's open access institutional repository after the conclusion of the competition. Entrants are surveyed after the competition so that their feedback can guide future iterations of the event, and the overall response has been extremely positive. The archived images have been featured in the UAlberta's alumni magazine, New Trail, on social media, as displays for meetings and in the Faculty of Graduate Studies and Research offices. The involvement of campus partners is a significant contributor to the ongoing success of the competition.
\end{abstract}

Introduction

The Images of Research competition (IOR) was launched in the 2015/16 academic year as part of a broader partnership with the Faculty of Graduate Studies and Research (FGSR) to enhance graduate student professional development (PD) and community building [2]. Graduate students are invited to submit a high-resolution image with a title and short description that highlights how the image relates to their research. Twenty-four semi-finalist images, as determined by an adjudication panel, form an exhibition that remains on display in a campus library for one month. Winners are announced at the opening reception for this exhibition. Together, the competition and the exhibition of winning and semi-finalist images showcase and preserve graduate student research in print and digital form, foster student engagement, and support graduate students' academic endeavours. IOR also serves as a form of library outreach, highlighting UAlberta Libraries' principles of open and responsive services [3].

In Canada, several associations and funding agencies have begun to promote graduate student professional development [4], [5], leading to a wide array of programs at post-secondary institutions aimed at encouraging these students to seek out learning opportunities beyond their discipline. While graduate students are broadly understood to be developing academic skills in the course of their research and coursework, there is increasing interest in a set of "transferable 
competencies of a broader nature [6]," which include interpersonal and communication skills. "All graduates need to be able to communicate effectively, concisely, and correctly in written, spoken, and visual forms to a variety of audiences using a wide range of media. Communication includes the effective sharing of knowledge and expertise in a variety of situations (to peers, to the general public and to decision makers) [4]." It is these communication skills that are targeted by the IOR competition.

In addition to fostering individual skill development, IOR also invites graduate students to engage with the broader research community on campus. This aligns with the larger institutional plan promoting engagement "across disciplines, campuses, faculties and units [7]," to enhance students' learning experiences. Participants who attend submission preparation workshops and the exhibition reception are able to interact with peers from other departments and reflect upon new methods of expression. The exposure to research topics and methods from many fields encourages students to re-imagine and contextualise their own work.

Prior to the inaugural competition, a library resident was tasked with reviewing and analysing similar events at other post-secondary institutions. Nine competitions were identified, and the resident librarian was able to correspond with organizers at seven of the host institutions in order to gain insight into their experiences [8]. The results of this analysis informed the timeline and procedures for the first event, which have since been refined over subsequent iterations of the competition. There was much variety among the events studied. Some schools held separate contests for undergraduate [9] and graduate students, while some were open to alumni, faculty and staff in addition to current students. Competitions were held at different points in the school year, and ranged in duration from one month to six months. While a few institutions awarded prizes in the form of e-readers or gift cards, most gave cash. The organizers of such competitions were primarily university Research Offices, with the help of such campus partners as the library, IT department, and marketing and communications departments.

\section{Methods}

The IOR competition takes place in the winter term, but promotion begins at the end of fall term in order to encourage graduate students to plan their submission over the break. Graduate students are invited to submit a 300 dpi-or-higher image, with title, plus a 200-word, plain-language description explaining how the image relates to their research. Participants must be current graduate students in good standing, and images must meet minimum size and resolution requirements that allow printing the images at a length of twenty-four inches on the short edge. Entries are accepted over a three week period from mid-January to early February.

Organizers and campus partners developed the Images of Research Submission Preparation Workshop for the purpose of offering guidance to graduate students who are interested in making a submission. For the 2018/2019 competition, the FGSR permitted the workshop to be applied towards PD credits, a graduation requirement of all graduate students at UAlberta. This two-hour workshop is offered twice: once prior to the competition opening date and once during the submission period. It is divided into four half-hour segments addressing design and technical aspects of creating an image, and is followed by a question and answer period. 
The first segment, delivered by a graphic designer or photographer, addresses artistic and design principles involved in creating compelling images, and challenges the students to consider what they want their image to communicate about their research, what creative processes they will use, and how to think about their image artistically, for example, using contrast, scale, repetition and pattern, or presenting an unusual perspective. The second segment is delivered by a print specialist from our partner Campus Design and Print Solutions to make sure images meet the technical requirements, and provides technical information and definitions, such as image resolution, file formats, PPI (pixels per inch) vs DPI (dots per inch), and camera settings.

One of the goals of this competition is to encourage the development of transferable competencies, such as clear communication skills, and so the third segment focuses on crafting a clear and concise explanation of their research. A local magazine editor introduced methods for capturing a reader's attention to encourage further reading, and students were given specific advice, e.g. use active verbs; write short, strong sentences; don't use jargon or cliches. The final segment, delivered by our copyright Librarian, explains the copyright implications of the Creative Commons license (CC BY 4.0) assigned to the images submitted to the competition. This segment also gives organizers the opportunity to discuss related concepts such as the value of open research.

Once the submission period closes, entries are checked for participant eligibility and to see that technical requirements have been met. Images that meet the all eligibility and technical requirements are subjected to a two-phase adjudication process by a panel of five to seven judges consisting of faculty, graduate students, and design or communications professionals. In the first phase, each judge is sent an individual link to a Qualtrics survey with all the eligible images and descriptions, and given one week to complete their initial, four-step evaluation:

1) Judges select any images they want to move forward for further consideration;

2) This initial selection is narrowed to a minimum of ten and maximum of twenty-five images;

3) Judges choose their ten final images;

4) These images are ranked into a "top ten."

Judges are provided with a holistic rubric (Table 1) to help guide their assessment. Entries are judged on their originality, aesthetic appeal, relationship between the image and the student's research, and clarity of written title and description. For the second phase, the adjudication panel meets in person to decide the semi-finalists and prize winners through a process of consensus. Prizes are awarded to the first, second and third place images, as well as two honourable mentions.

The top twenty-four images are selected as semi-finalists and subjected to online voting to determine a People's Choice award winner. People's Choice voting has in some years been restricted to the university community and in others opened to the public; some graduate students have indicated a preference for restrictions to this vote. All competitors grant permission to include their entry in our open access institutional repository at the time of submission, and the 
winners and semi-finalists are uploaded after the conclusion of the competition. Prize winners, including People's Choice winners, are not eligible to enter future competitions, but other entrants, including semi-finalists, are welcome to re-submit with a new image. Organizers view the presence of repeat competitors over the years as a measure of the competition's success.

Table 1: IOR Evaluation Rubric

\begin{tabular}{|c|c|c|}
\hline Exceptional & Adequate & Unsatisfactory \\
\hline $\begin{array}{l}\text { Overall originality/creativity } \\
\text { - The combined written } \\
\text { and visual content } \\
\text { communicate a unique, } \\
\text { exciting and/or inventive } \\
\text { treatment of the subject }\end{array}$ & $\begin{array}{l}\text { Overall originality/creativity } \\
\text { - The combined written } \\
\text { and visual content } \\
\text { communicate a new, } \\
\text { interesting and/or } \\
\text { thoughtful treatment of } \\
\text { the subject }\end{array}$ & $\begin{array}{l}\text { Overall originality/creativity } \\
\text { - The combined written } \\
\text { and visual content are not } \\
\text { particularly } \\
\text { communicative or } \\
\text { interesting }\end{array}$ \\
\hline $\begin{array}{l}\text { Aesthetic appeal of the image } \\
\text { - Overwhelmingly } \\
\text { captivates viewer's } \\
\text { attention } \\
\text { - Triggers a strong, } \\
\text { identifiable emotional } \\
\text { response }\end{array}$ & $\begin{array}{l}\text { Aesthetic appeal of the image } \\
\text { - Visually appealing } \\
\text { - Triggers an emotional } \\
\text { response }\end{array}$ & $\begin{array}{l}\text { Aesthetic appeal of the image } \\
\text { - Lacking in appeal either } \\
\text { visually or emotionally }\end{array}$ \\
\hline $\begin{array}{l}\text { Relationship between the } \\
\text { image and the research topic } \\
\text { - The image powerfully } \\
\text { represents the research } \\
\text { topic } \\
\text { - Compels viewer to } \\
\text { engage with the research }\end{array}$ & $\begin{array}{l}\text { Relationship between the } \\
\text { image and the research topic } \\
\text { - The image clearly } \\
\text { represents the research } \\
\text { topic } \\
\text { - Invites viewer to engage } \\
\text { with the research }\end{array}$ & $\begin{array}{l}\text { Relationship between the } \\
\text { image and the research topic } \\
\text { - The relationship between } \\
\text { the image and research is } \\
\text { unclear or non-existent }\end{array}$ \\
\hline $\begin{array}{l}\text { Clarity of written description } \\
\text { and title } \\
\text { - Title and description are } \\
\text { beautifully and } \\
\text { masterfully constructed, } \\
\text { and clearly communicate } \\
\text { the research topic's } \\
\text { significance in language } \\
\text { appropriate to a } \\
\text { non-specialist audience }\end{array}$ & $\begin{array}{l}\text { Clarity of written description } \\
\text { and title } \\
\text { - Title and language } \\
\text { clearly communicate the } \\
\text { research topic and/or its } \\
\text { significance, but are not } \\
\text { compelling (e.g. use of } \\
\text { jargon, overly complex } \\
\text { sentences) }\end{array}$ & $\begin{array}{l}\text { Clarity of written description } \\
\text { and title } \\
\text { - Title and description } \\
\text { poorly communicate the } \\
\text { research topic and its } \\
\text { significance, and/or is } \\
\text { poorly constructed (e.g. } \\
\text { poor spelling or } \\
\text { grammar) }\end{array}$ \\
\hline
\end{tabular}

Prize winners are announced at a catered reception in the library where an exhibition of the winning and semi-finalist entries remains on display for approximately one month. UAlberta has five publicly accessible libraries on its north campus; the reception and exhibition will change 
venues every other year to help broaden exposure to the competition and the research it showcases. The Science and Technology Library was the first host, followed by the Education Library. The Health Sciences and Humanities \& Social Sciences Libraries will be considered for future competitions.

Feedback is requested from both participants and judges after the close of the competition in order to guide improvements in competition design and delivery for future years. Participants are surveyed with a five-question Google Form (Figure 1) to determine how they heard about the competition and whether they were satisfied with their experience. The responses inform both competition design and promotion efforts in future years. For example, due to participant feedback, communication procedures have been improved to keep participants aware of their status as the competition progresses. Judges are asked for their input at the end of the adjudication meeting, when the process is still fresh in their minds. Suggestions are noted by organizers for inclusion in the annual close-out report, and have led to such initiatives as the addition of the clear communication segment of the submission preparation workshop.

Figure 1: Participant Feedback Form

1. How did you hear about the competition? (Please check all that apply)

$\square$ FGSR Grad News

$\square$ FGSR email/listserv

$\square$ GSA email/listserv

$\square$ Department or librarian email/listserv

$\square$ University website (www.ualberta.ca)

$\square$ Library website or blog

$\square$ Campus TVs

$\square$ Social media (Twitter, Instagram, Facebook)

$\square$ Other

2. Did you find the instructions on the website easy to follow?
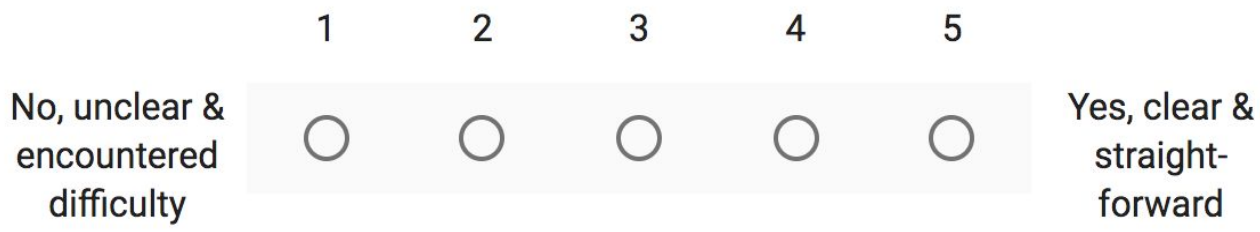

3. Would you recommend the competition to your fellow graduate students?

$\bigcirc$ Yes

No

Other:

4. Overall, how would you describe your experience with the Images of Research competition? (e.g. what did you like)

5. Any final suggestions or feedback? 
Results

Graduate student enrollment has been approximately 7500 students each year of the IOR competition. The number of entries received for the competition has remained consistent each year at approximately 100 . Organizers have also noted approximately $7 \%$ repeat participants, including former semi-finalists who have gone on to win prizes. Entries come from across all faculties, and often showcase photographs taken in a range of settings: in the city, in national parks, in the arctic, in the desert and even in space. However, there is no requirement that the entry be a photograph. Submissions have also included other forms of digitally created visual representations of student work.

Certain types of research projects, such as work with vulnerable populations or wildlife cameras, don't allow for high-resolution photography. Graduate students have shown exceptional creativity in finding ways to create, combine or enhance images to convey the essence of their work. However, after several entries had to be disqualified for lack of compliance with the technical requirements, additional information was added to the online FAQs in an attempt to clarify this aspect of the rules. Examples of disqualified entries include images that were too small (e.g. less than one square inch) or at too low a resolution (e.g. 72 dpi when 300 is the required minimum). Manipulation of images to achieve the required specifications leads to very low-quality prints, and is not allowed.

During the planning phase of the most-recent competition, organizers attempted to contact all previous contestants and judges with a two-question survey in order to gain insight into their experiences with Images of Research. Previous contestants were asked how participation in IOR 1) supported their professional development, and 2) enhanced their student experience. Out of 292 previous participants, thirty responses were received for a response rate of $10 \%$. Thirteen respondents (43\%) recognized some benefit to their professional development, and twenty (67\%) noted positive experiences engaging beyond their departments.

Judges were asked to describe 1) their motivation for serving on the adjudication panel, and 2) how their experience affected their perception of research at the University of Alberta. Out of nineteen previous judges, ten responses were received for a response rate $53 \%$. Reasons for serving as a judge were varied, from a specific interest in visual communication to simple curiosity. The most common theme to emerge from the question on perception of research was an appreciation for the breadth of research on campus, reported by seven of the ten respondents.

\section{Discussion}

Responses to the question regarding professional development were split between those who didn't find value in the process, and those who offered insightful comments on what they had learned. It is rewarding to read responses such as these:

"The creation of the image itself and the supporting documentation prompted me to consider very carefully how I communicate my research to the world. It provided a great 
outlet to experiment with new forms of communication and has encouraged me to continue scientific communication in other non-traditional ways"

"...it made me realize that writing is not the only way to disseminate research. There is something powerful about images ... and it made me rethink the way I approach research and my work. Also, having them published with DOI is also a game-changer."

"This competition allowed me to explore my research through a different framework and made [me] consider how I wanted my research to be communicated to people outside of my field."

However, it was disheartening to find that half the respondents didn't recognize any benefit to their professional development. While the competition is only one component of a larger program of PD opportunities offered by FGSR, IOR organizers should consider strategies to encourage metacognitive learning for future competitions in order to fully realize the potential for development of additional skills. The workshops offer an ideal venue to highlight the desired individual outcomes for those students who attend.

Participant responses regarding engagement were more consistent, with two thirds of respondents reporting positive experiences. Sample comments include:

"It's easy for a graduate degree (in engineering especially) to become overwhelmingly technical, and narrowly specific to a discipline. The Images of Research competition provided me with an opportunity to step outside of that norm and bring in interdisciplinary ideas and forms of expression. At the very least this provided an escape from monotonous drudgery... but I suspect any foray into interdisciplinary thought has effects more far-reaching and meaningful than that."

"I enjoyed seeing the other contributions and getting to know the other participants."

"I got to meet other participating students and hear about research I wouldn't have otherwise. Really helped me to feel like a part of a bigger university community!"

In addition to fostering community among the participants, the month-long exhibition in the library offers an opportunity to showcase the variety of research topics being explored on campus to all those who use this space. The Faculty of Graduate Studies and Research is planning an additional reception to highlight the competition to off-campus partners, expanding the reach beyond the campus community.

Graduate students are not the only ones to benefit from participation in the competition. Adjudicators have different motivations for taking on the role, for example:

"I wanted to get a first-hand look at what kinds of graduate research is happening at the University of Alberta, and I wanted to test my ability to critically evaluate information. I 
also wanted more real-world experience of working with professionals to reach decisions in which it felt like my input mattered."

"Interest in the power of visualization, how imagery can help to capture complex aspects of scientific research in an accessible and impactful way; interest in transmediation."

They come from diverse academic backgrounds and bring experience from different disciplines, but emerge from the process with a new understanding of research on campus:

"It helped me to better understand the variety of projects and the passions -- both personal and for societal change -- that drive them."

"It was interesting to have another, non-traditional, view into how graduate students think about their research. This format makes unfamiliar areas of research more accessible."

"It broadened and deepened my understanding of the research that is done and how that gets presented and represented to a broader audience."

As a function of UAlberta Libraries' values for open information and services, all semi-finalist images are deposited to ERA, our institutional repository, under a CC BY 4.0 license, which allows others to copy, distribute, remix, tweak, and build upon the images as long as appropriate credit and acknowledgement of any changes made is given. By archiving the images and their descriptions, we are creating a legacy not only of UAlberta research activities, but the library's commitment to future scholars. This practise has already proven to be of value to the UAlberta community. Several of the images have appeared in our alumni magazine, on social media, and as displays for meetings and in the Faculty of Graduate Studies and Research offices. At least one previous winner has continued to use their image in ongoing research-related communications activities.

UAlberta Libraries takes the lead in organizing and running the Images of Research competition, but it would not be possible without the help of campus partnerships. The organizing committee includes at least one representative from the Faculty of Graduate Studies and Research who helps avoid conflicts with other graduate student events, ensures workshops qualify for PD credit, and provides the means of verifying participant eligibility. Campus Design \& Print Solutions is responsible for evaluating compliance with technical specifications, printing and mounting the images for the reception, and assisting in workshop development and delivery. IOR is also building informal relationships on campus. After serving as a judge, the editor of New Trail offered her services in leading the clear writing workshop and promoted the use of the openly-licensed images available in ERA.

\section{Conclusion}

The Images of Research competition increases community awareness of research activities at the University of Alberta; feedback from participants and judges describes the positive impact of this awareness. Benefits of participation for graduate students include the development of 
transferable professional skills, such as an ability to succinctly write about research in plain language and use non-traditional methods of representation and communication of research. Competitors also enhance their student experience through the opportunity to establish

relationships with other students/researchers. Participant feedback indicates the need to adapt preparation materials to raise awareness of these benefits.

Adjudicators also benefit from their participation in the competition; they gain a heightened awareness of research on campus, and develop excitement for the student researchers and their work, especially in judges from professional associations outside the immediate University of Alberta community.

Images of Research contributes to the legacy of UAlberta research in our library spaces and institutional repository, and offers opportunities for engagement within the campus community and beyond.

\section{References}

[1] ERA (Education and Research Archive). Available: https://era.library.ualberta.ca/.

[2] Images of Research. Available: https://www.library.ualberta.ca/images-of-research.

[3] University of Alberta Libraries, "UAL strategic priorities 2017/2018," 2017.

[4] Canadian Association for Graduate Studies, "Professional skills development for graduate students," Ottawa, 2008.

[5] R. Polziehn, "Skills expected from graduate students in search of employment in academic and non-academic settings," 2011.

[6] M. Rose, "Graduate student professional development: A survey with recommendations," Social Sciences and Humanities Research Council (SSHRC), Ottawa, Mar. 2012.

[7] Anonymous "For the public good," University of Alberta, 2016.

[8] D. Wagner, "Images of Research: Background Report and Recommendations," unpublished.

[9] M. Reed and M. K. Hensley, "Image of research: Celebrating and sharing undergraduate work," in Undergraduate Research and the Academic Librarian: Case Studies and Best Practices, M. K. Hensley and S. Davis-Kahl, Eds. Chicago: Association of College and Research Libraries, 2017, pp. 157-172. 